\title{
Understanding Dissolved Organic Matter Reactivity and Composition in Lakes and Streams Using Proton-Transfer-Reaction Mass Spectrometry (PTR-MS)
}

\author{
Mike Peacock, ${ }^{*}{ }^{\dagger}$ Dušan Materić, ${ }^{\ddagger}$ Dolly N. Kothawala, ${ }^{\S}$ Rupert Holzinger, ${ }^{\ddagger}$ and Martyn N. Futter ${ }^{\dagger}$ \\ ${ }^{\dagger}$ Department of Aquatic Sciences and Assessment, Swedish University of Agricultural Sciences, Lennart Hjelms väg 9,75651 \\ Uppsala, Sweden \\ ${ }^{\ddagger}$ Institute for Marine and Atmospheric Research, Faculty of Science, Utrecht University, Princetonplein 5, 3584 CC Utrecht, The \\ Netherlands \\ ${ }^{\S}$ Department of Limnology, Evolutionary Biology Centre, Uppsala University, Norbyvägen 18D, 75236 Uppsala, Sweden
}

Supporting Information

\begin{abstract}
Here, we present a novel approach for investigating dissolved organic matter (DOM) composition using thermal desorption protontransfer-reaction mass spectrometry (PTR-MS), a technique that provides insight into the molecular composition of DOM $<m / z 500$ (termed "PTRDOC"). The applicability of PTR-MS for understanding the relationship between DOM composition and reactivity has yet to be explored. We present results from a synoptic sampling campaign of streams and lakes in a Swedish forest catchment where we measured DOM composition using PTR-MS and traditional optical methods and conducted DOM biodegradability assays. PTR-DOC comprised $\leq 12 \%$ of the total DOC pool. We found significant relationships between PTR-DOC and DOM degradability; reduced chemodiversity and low concentrations of PTR-DOC were both associated with the total DOM pool being more susceptible to microbial degradation. Furthermore, molecular differences were apparent among headwater lakes, headwater streams, and lakes further down the catchment. Direct linkages between PTR-DOC and optical methods were observed. Using the quantitative data that PTR-MS generates, it could become possible to identify the fluorescing components of DOM, and the method may be particularly informative in low-DOC waters such as marine environments where PTR-DOC may dominate the total DOM pool.
\end{abstract}

\section{INTRODUCTION}

The importance of inland waters in the global carbon cycle is well recognized. ${ }^{1}$ Lakes process dissolved organic matter (DOM), either by complete degradation, which results in emissions of carbon dioxide and methane, or by partial degradation, which causes larger DOM molecules to be broken down into smaller molecules. ${ }^{2}$ These processes therefore depend on, and can influence, the composition of $\mathrm{DOM}^{3}$ which, in turn, is influenced by catchment land cover (e.g., forest, mire, or agriculture), climate, and water residence times. ${ }^{4,5}$ As a result, the age of DOM varies throughout the aquatic continuum. In general, older DOM is less reactive and contains a greater proportion of autochthonous (internally produced) material. ${ }^{6}$

DOM composition can be investigated using numerous methods of varying complexity. Simple methods, including absorbance and fluorescence spectroscopy, generate metrics such as specific ultraviolet absorbance (SUVA) and a suite of quality indices ${ }^{7}$ that act as proxies for molecular structure and the degree of autochthonous DOM production. ${ }^{8,9}$ More complex methods, including thermochemolysis gas chromatography and mass spectrometry (GC-MS) and ${ }^{13} \mathrm{C}$ nuclear magnetic resonance spectroscopy, provide direct information about functional group composition ${ }^{10}$ and DOM aromaticity. ${ }^{8}$ Fourier transform ion cyclotron resonance mass spectrometry (FT-ICR MS) is widely used to identify individual DOM molecular constituents and provide new insights into DOM dynamics. ${ }^{11,12}$ Similarly, Orbitrap MS has been suggested as a viable, more widely accessible alternative to FT-ICR MS. ${ }^{13}$

Proton-transfer-reaction mass spectrometry (PTR-MS) is a novel method for molecular analysis of aquatic DOM. ${ }^{14}$ PTRMS has previously been used to measure gaseous volatile organic compounds and organic aerosol composition. ${ }^{15-17}$ For instance, the method was able to identify differences in DOM composition between intact and degraded tropical peatlands. ${ }^{14}$ The method is fast, and the only pretreatment required to analyze aquatic samples is evaporation/sublimation, leaving behind the residue of organic matter for analysis. ${ }^{14}$ Unlike Fourier transform-based methods, PTR-MS is quantitative (i.e., it provides actual concentrations of individual ions) and is unique in this respect among high-resolution MS methods.

Received: October 4, 2018

Revised: November 2, 2018

Accepted: November 5, 2018

Published: November 5, 2018 
Table 1. Details of Sampling Sites Showing Water Body Type (HWL, headwater lake; DSL, downstream lake; HWS, headwater stream; S, stream draining a lake), Water $\mathrm{pH}$, and Dissolved Organic Carbon (DOC) Concentration and PTR-DOC Metrics Such as Ratios of Hydrogen to Carbon Atoms (H/C), Ratios of Oxygen to Carbon Atoms (O/C), Concentrations of DOC Measured by Proton-Transfer-Reaction Mass Spectrometry (PTR-MS) Normalized against DOC Concentration (\%PTRDOC), Mean Oxidative States of Carbon (OSC), Mean Numbers of Carbon Atoms per Molecule ( $n$ C), Molecular Chemodiversity, and Numbers of Ions ${ }^{a}$

\begin{tabular}{|c|c|c|c|c|c|c|c|c|c|c|c|}
\hline & $\begin{array}{c}\text { water body } \\
\text { type }\end{array}$ & $\mathrm{pH}$ & $\begin{array}{c}\text { DOC } \\
\left(\mathrm{mg} \mathrm{L}^{-1}\right)\end{array}$ & $\mathrm{H} / \mathrm{C}$ & $\mathrm{O} / \mathrm{C}$ & $\begin{array}{l}\text { \%PTR- } \\
\text { DOC }\end{array}$ & OSC & $n \mathrm{C}$ & chemodiversity & $\begin{array}{l}\text { no. of } \\
\text { ions }\end{array}$ & $\begin{array}{c}k \mathrm{O}_{2} \\
\left(\text { day }^{-1}\right)\end{array}$ \\
\hline Gaffeln & HWL & 6.2 & 4.80 & 1.51 & 0.42 & 11.8 & -0.62 & 3.81 & 4.07 & 301 & 0.001 \\
\hline Gaffeln Stream & S & 6.0 & 9.24 & 1.50 & 0.46 & 3.9 & -0.52 & 3.49 & 3.89 & 300 & 0.012 \\
\hline Stora Hästevatten North & HWL & 6.5 & 3.43 & 1.42 & 0.36 & 9.4 & -0.64 & 4.52 & 4.08 & 294 & 0.077 \\
\hline Stora Hästevatten South & HWL & 6.5 & 4.06 & 1.47 & 0.39 & 10.2 & -0.64 & 4.11 & 4.07 & 301 & 0.037 \\
\hline Gårdsjön inflow & DSL & 6.7 & 7.33 & 1.50 & 0.41 & 11.3 & -0.63 & 3.94 & 4.06 & 302 & 0.023 \\
\hline F1 stream & HWS & 4.6 & 14.56 & 1.39 & 0.51 & 0.8 & -0.31 & 3.03 & 3.46 & 260 & 0.325 \\
\hline F2 stream & HWS & 4.8 & 43.29 & 1.46 & 0.49 & 0.4 & -0.43 & 3.15 & 3.67 & 289 & 0.277 \\
\hline F3 stream & HWS & 4.9 & 16.25 & 1.34 & 0.34 & 1.8 & -0.63 & 4.90 & 3.83 & 294 & 0.107 \\
\hline Gårdsjön outflow & DSL & 6.9 & 6.19 & 1.47 & 0.40 & 5.5 & -0.62 & 4.09 & 4.01 & 299 & 0.029 \\
\hline Stora Bjurevatten & DSL & 7.0 & 9.68 & 1.49 & 0.48 & 3.3 & -0.47 & 3.40 & 3.80 & 292 & 0.165 \\
\hline Västersjön & DSL & 7.2 & 8.68 & 1.52 & 0.47 & 1.6 & -0.53 & 3.43 & 3.78 & 266 & 0.037 \\
\hline
\end{tabular}

While it is optimized to target low-molecular weight (LMW) $(\leq 500 \mathrm{~m} / z) \mathrm{DOM}$ and targets a small fraction of the total DOM pool, how this relates to DOM optical properties and reactivity remains unknown. To address this knowledge gap, we collected samples from seven lakes and four streams in a boreal forest catchment and analyzed them using PTR-MS. We also used traditional optical metrics of DOM composition and investigated DOM degradability with an incubation study.

\section{MATERIALS AND METHODS}

Sampling was undertaken on August 19, 2017, in the Gårdsjön research catchment in southwest Sweden (Table S1 and Figure $\mathrm{S} 1)$. The climate is temperate, and the annual precipitation is $700-1200 \mathrm{~mm}$. The altitude is $100-170 \mathrm{~m}$ above sea level. ${ }^{18}$ The catchment is predominantly forest covered with Picea abies and Pinus sylvestris and small areas (10\%) of mire. Soils are mainly thin podzols, with bedrock outcrops. ${ }^{18}$ The sampling included 11 sites: three headwater lakes, the inflow and outflow of Gårdsjön, three headwater streams draining wholly terrestrial catchments, and one stream draining a headwater lake. Additionally, we sampled two nearby brownwater lakes that had much larger catchments.

Samples for DOM degradability analyses were filtered in situ with prerinsed cellulose acetate $1.2 \mu \mathrm{m}$ filters and collected in precombusted $40 \mathrm{~mL}$ glass vials. Samples were stored overnight in the dark at $20{ }^{\circ} \mathrm{C}$ and transported to the laboratory ( $6 \mathrm{~h}$ journey) where they were stored in a dark incubator at $20{ }^{\circ} \mathrm{C}$. These samples were used to measure oxygen $\left(\mathrm{O}_{2}\right)$ concentration as a proxy for bacterial respiration. ${ }^{19}$ A PreSens $\mathrm{O}_{2}$ sensor spot (PreSens $\mathrm{GmbH}$, Regensburg, Germany) placed on the inner wall of each vial allowed for non-invasive measurement of $\mathrm{O}_{2}$ concentrations with a PreSens Fibox 3. The first $\mathrm{O}_{2}$ reading was taken after all samples had been collected and allowed to adjust to the ambient temperature. Measurements were taken twice a day for the first 4 days and then once a day for 3 days (7 day incubation). We plotted log-transformed oxygen concentrations against time and calculated slopes for each sample, representing first-order oxygen decay rate constants $\left(\mathrm{kO}_{2}\right)$.

Samples for DOM composition using optical analysis were collected in $100 \mathrm{~mL}$ glass bottles, filtered in situ with prerinsed
$0.45 \mu \mathrm{m}$ cellulose nitrate filters, and then stored in the dark at $4{ }^{\circ} \mathrm{C}$. They were transported on ice the following day to the laboratory. Dissolved organic carbon (DOC) concentrations were measured as nonpurgeable organic carbon on a Shimadzu TOC- $\mathrm{V}_{\mathrm{CPH}}$ instrument (Shimadzu, Kyoto, Japan). The fluorescence and absorbance were measured on an Aqualog spectrofluorometer (Horiba, Kyoto, Japan), and from this, we calculated the fluorescence index, ${ }^{20}$ freshness index, ${ }^{9}$ humification index, ${ }^{21}$ SUVA, $^{8}$ and fluorescence peaks ${ }^{22}$ (detailed in the Supporting Information).

To prepare samples for PTR-MS analysis, ${ }^{14}$ a low-pressure evaporation/sublimation system removed water from the samples, leaving residues of semivolatile and nonvolatile OM. The samples were then thermally desorbed at $250{ }^{\circ} \mathrm{C}$ and measured using a PTR-TOF 8000 instrument (IONICON Analytik, Innsbruck, Austria). Five of the samples were analyzed in duplicate, and the reproducibility was comparable to those of other MS methods (Bray-Curtis dissimilarity = 5.24\%). Peak identification and integration were performed using PTRwid. ${ }^{23}$ Chemical formulas were assigned using PTRwid and mMass ${ }^{24}$ and classified into structural groupings (e.g., aliphatic). ${ }^{25}$ We term the output of this analysis "PTRDOC”. The PTR-DOC metrics O/C, H/C, mean oxidative state of carbon (OSC), and mean number of carbon $(n \mathrm{C})$ atoms per molecule were calculated for each sample. Percent PTR-DOC was calculated as the sum of individual ion concentrations multiplied by the ion-specific $\mathrm{C}$ mass fraction obtained from the chemical formulas and expressed as a percentage of the DOC concentration from the Shimadzu instrument. We used Shannon's index of diversity ${ }^{26}$ as a measure of chemodiversity (see the Supporting Information for further PTR-MS information).

We conducted principal component analysis (PCA) using Canoco 5.0, with $\mathrm{pH}$, DOC concentration, PTR-DOC metrics (listed above), and fluorescence and absorbance metrics to investigate differences in DOM quality. We used Pearson's correlation coefficient to test for relationships between individual ions and DOM fluorescence and absorbance metrics. ${ }^{27}$ For these tests, we included only ions that were detected in all samples. Additionally, we performed Pearson correlation analyses using the PTR-DOC metrics. Correlation 
analyses were performed using SPSS Statistics 24, with a significance level set at $p<0.05$.

\section{RESULTS AND DISCUSSION}

PTR-MS detected a total of 314 unique ions across the data set ranging from $\mathrm{m} / z 27.023$ to 395.374 (Figures S2 and S3), which corresponded to a mean of $5.5 \%$ of the measured DOC pool (\%PTR-DOC in Table 1). Aliphatic ions were most numerous (72), followed by condensed aromatics (63), aromatics (60), and peptides (63); 246 of the ions were found in all samples. Mean ion concentrations ranged over multiple orders of magnitude and generally declined with increasing $\mathrm{m} / \mathrm{z}$ values. Two of the three streams had small numbers of ions and low chemodiversity, as did two downstream lakes (Bjurevatten and Västersjön). In contrast, the three headwater lakes had the highest chemodiversity (Table 1). The percent of total DOC detected by PTR-MS (\% PTR-DOC) was lowest in the headwater streams and for all samples was inversely related to the log-transformed DOC concentration (Figure S4; $r^{2}=0.62 ; p=0.004$ ). PCA showed that headwater streams grouped distinctly from lakes and the stream with an upstream lake (Figure 1). Specifically, streams

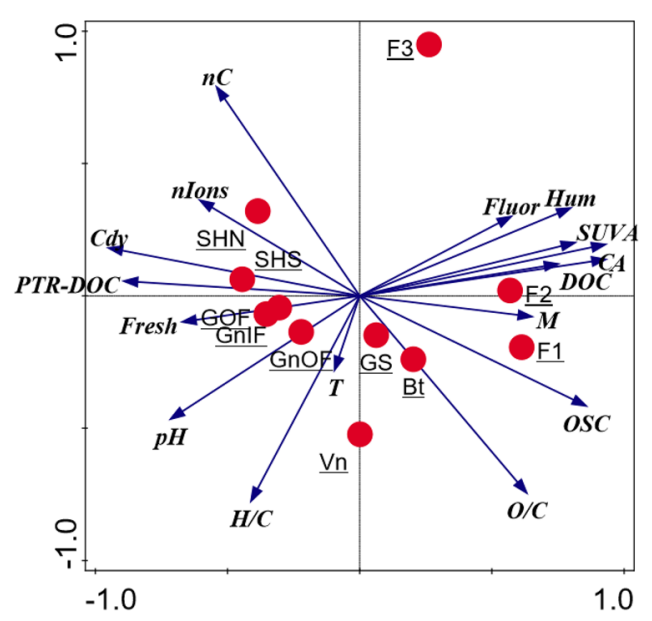

Figure 1. Principal component analysis (PCA) of $\mathrm{pH}$ and dissolved organic matter (DOM) composition. Circles indicate sampling sites, while DOM metrics are shown in bold. Site codes are underlined: Gaffeln (GOF), Gaffeln Stream (GS), Stora Hästevatten North (SHN), Stora Hästevatten South (SHS), Gårdsjön inflow (GnIF), F1 stream (F1), F2 stream (F2), F3 stream (F3), Gårdsjön outflow (GnOF), Stora Bjurevatten (Bt), and Västersjön (Vn). PTR-DOC metrics: ratio of hydrogen to carbon atoms $(\mathrm{H} / \mathrm{C})$, ratio of oxygen to carbon atoms $(\mathrm{O} / \mathrm{C})$, concentration of DOC measured by protontransfer-reaction mass spectrometry (PTR-MS) normalized against DOC concentration (PTR-DOC), mean oxidative state of carbon (OSC), mean number of carbon atoms per molecule $(n \mathrm{C})$, molecular chemodiversity (Cdv), and number of ions (nIons). DOM metrics from fluorescence and absorbance: fluorescence index, freshness index, humification index, SUVA, and fluorescence peaks C, A, M, and T. $53 \%$ of the variation is explained on the horizontal axis, and $16 \%$ on the vertical axis.

were defined by high values for DOC, SUVA, humification and fluorescence indices, and fluorescence peaks $\mathrm{A}$ and $\mathrm{M}$. Upstream lakes were defined by higher values for chemodiversity, \%PTR-DOC, freshness index, and total number of ions detected. The two lakes farthest downstream, Bjurevatten and Västersjön, were defined by higher values for $\mathrm{O} / \mathrm{C}$ and $\mathrm{H}$ / C. Running a PCA using only the concentrations of ions detected resulted in similar groupings being detected between sites (Figure S5). Notably, the headwater streams clustered separately from the lakes on both analyses, and the two downstream lakes were close to one another.

First-order oxygen consumption rate constants $\left(k \mathrm{O}_{2}\right)$ varied considerably, from 0.001 to $0.325 \mathrm{day}^{-1}$. Significant correlations were found between $\mathrm{kO}_{2}$ and three PTR-DOC metrics: OSC $(r=0.84)$, chemodiversity $(r=0.86)$, and \% PTR-DOC $(r=-0.80)$ (Figure 2). Furthermore, significant correlations were detected between $\mathrm{kO}_{2}$ and 70 individual ions, meaning $28.5 \%$ of ions significantly correlated (mean absolute $r=0.64$; mean $p=0.036$ ) (Table S3). Of these correlations, 67 were negative and only three were positive. The majority of correlated ions were peptides (21), aromatics (13), and condensed aromatics (19).

Three PTR-DOC metrics, \%PTR-DOC, OSC, and chemodiversity, showed significant correlations with fluorescence and absorbance measures of DOM composition (mean absolute $r=$ 0.73 ; mean $p=0.017$ ) (Table 2). Additionally, we found 21 ions that had significant correlations with optical measures of DOM composition (mean absolute $r=0.64$; mean $p=0.032$ ) (Table S4). For this analysis, we included only ions that were detected in all samples, giving a total of 246 . Thus, $8.5 \%$ of ions had nominally significant correlations.

PTR-MS detected proportionally less of the total DOC pool in headwater streams. These streams drain highly organic peat soils $^{28}$ that typically have humic, HMW DOM that is less likely to be detected by PTR-MS, which, in this study, principally targets $\mathrm{DOM}<m / z 500$. Our findings show that headwater streams (i.e., "new" water) generally have fewer ions and lower chemodiversity of PTR-DOC. Other work in boreal forests has shown that extensive degradation of LMW DOM occurs at the soil-stream interface, ${ }^{29}$ which could explain the observed lack of chemodiversity in our headwater streams when compared to that of lakes. The small sample size makes robust statistical analysis unwise, but these data suggest that DOM composition in streams draining small, terrestrially dominated catchments can vary considerably across small spatial scales.

The headwater lakes had high chemodiversity and proportionally more PTR-DOC. These are clear, low-DOC lakes, so it is likely that autochthonous production and photochemical production result in more PTR-DOC in these systems. ${ }^{30}$ As water moves through the catchment, highly humic autochthonous DOM enters the system from wetlands and headwater streams. In downstream, brownwater lakes, microbial processes should lead to decreases in LMW DOM. ${ }^{31}$ Our analysis shows some indication of this, with an increased level of DOM oxidation, a smaller number of $\mathrm{C}$ atoms per molecule, and less PTR-DOC as a percentage of total DOC in downstream waters. All of these can be considered signatures of DOM processing. ${ }^{14}$ Indeed, the proportion of PTR-DOC to total DOC is approximately halved between the inflow and outflow of Gårdsjön and declines again in the next lake down the catchment, presumably as a result of DOM processing and also due to the input of DOM from headwater streams. Furthermore, of all the lakes sampled, chemodiversity and the total number of ions were lowest in Bjurevatten and Västersjön. These brownwater lakes have large catchments and will receive older water with highly processed DOM from upstream lakes and streams. This is consistent with other studies that reported molecular alterations related to the aging and reworking of DOM. ${ }^{27,32}$ 

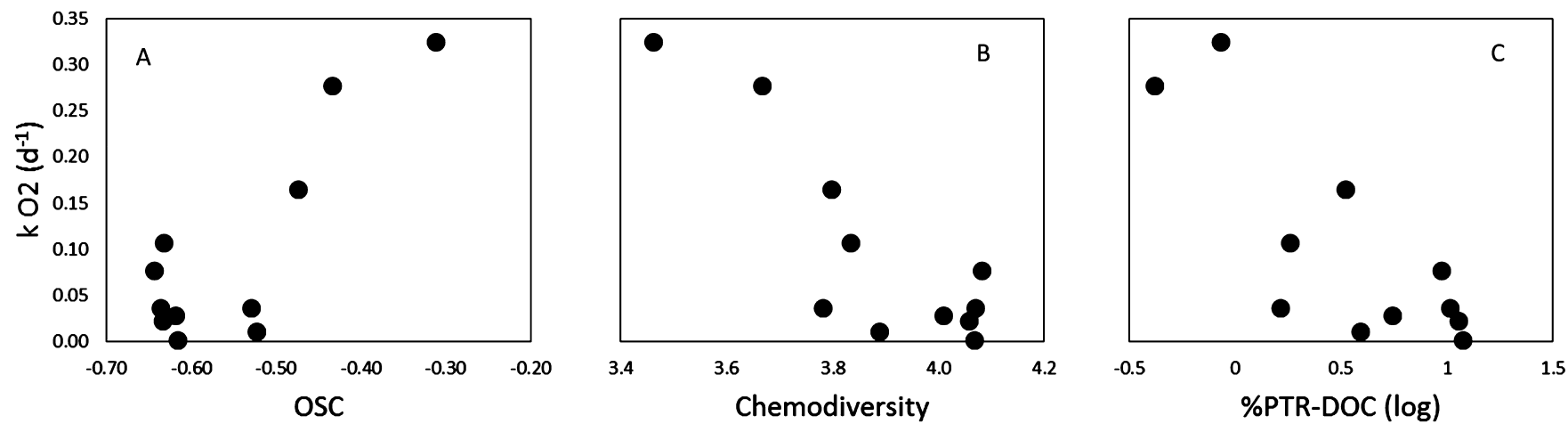

Figure 2. Scatter plots between first-order oxygen decay rates $\left(k \mathrm{O}_{2}\right)$ and $(\mathrm{A})$ the mean oxidative state of carbon $(\mathrm{OSC})(r=0.84 ; p=0.001),(\mathrm{B})$ molecular chemodiversity $(r=-0.86 ; p=0.001)$, and $(\mathrm{C})$ the total concentration of DOC measured by proton-transfer-reaction mass spectrometry (PTR-MS) normalized against DOC concentration (log-transformed) (\%PTR-DOC) $(r=-0.80 ; p=0.003)$.

Table 2. Pearson $r$ Values and Nominal $p$ Values (in parentheses) for Significant $(p<0.05)$ Correlations between PTR-DOC Metrics and Fluorescence and Absorbance Metrics $^{a}$

\begin{tabular}{lrll} 
& \%PTR-DOC & OSC & chemodiversity \\
\hline SUVA & $-0.73(0.01)$ & & $-0.73(0.012)$ \\
freshness & $0.62(0.044)$ & & \\
humification & $-0.66(0.028)$ & & $-0.62(0.041)$ \\
peak A & $-0.85(0.001)$ & $0.68(0.02)$ & $-0.82(0.002)$ \\
peak C & $-0.82(0.002)$ & $0.68(0.021)$ & $-0.81(0.003)$ \\
peak M & $-0.70(0.017)$ & &
\end{tabular}

${ }^{a}$ PTR-DOC metrics are the total concentration of DOC measured by proton-transfer-reaction mass spectrometry (PTR-MS) normalized against DOC concentration (\%PTR-DOC), the mean oxidative state of carbon (OSC), and molecular chemodiversity.

Both the bulk molecular signal and individual ions detected by PTR-MS were significantly related to DOM degradability, as measured by optode experiments. Such experiments can be informative measures of bacterial respiration and carbon processing. ${ }^{19,33,34}$ Correlation analyses produced statistically significant relationships between $\mathrm{O}_{2}$ losses and both DOM chemodiversity and the oxidation state of carbon. Specifically, the lower the chemodiversity and the more oxidized the PTRDOC, the more susceptible the total DOM pool appears to be to rapid microbial consumption. Furthermore, our findings show that as the amount of PTR-DOC increases (either as a proportion of the total DOC concentration or as individual ions), DOM degradability decreases, suggesting that a higher concentration of PTR-DOC is associated with a recalcitrant bulk DOM pool. This contrasts with research showing that LMW compounds such as dissolved free carboxylic acids can be important microbial substrates, ${ }^{35}$ although we observed few of these compounds in our samples, presumably because of their high volatility. It could be that HMW compounds are more bioavailable ${ }^{36}$ or that chemical structure (OSC and chemodiversity) is a more informative indicator of DOM reactivity, ${ }^{37}$ but it is also important to consider that some PTRDOC is likely to be generated during analysis, by fragmentation of larger ions (see the Supporting Information).

This is the first use of PTR-MS to characterize DOM across the aquatic continuum. Despite our relatively small sample size, we observed several statistically significant correlations between PTR-DOC and optical analyses. Furthermore, PCA found similar groupings of sample sites when it was performed on either the optical data or the molecular data. Relationships have been found between molecular formulas generated by FTICR-MS and optical indices for DOM from rivers, wetlands, and seas, ${ }^{25,27,38}$ but our data provide evidence that PTR-DOC behaves like the bulk DOM pool measured by absorbance and fluorescence.

In conclusion, PTR-MS is a useful tool for understanding DOM. It provides detailed molecular information about DOM composition and appears to act as a proxy for the bulk DOM pool. Furthermore, PTR-DOC can comprise a significant portion of total DOC and significantly relates to the degradability of the total DOM pool. Future studies with PTR-MS analysis before and after incubation would elucidate whether PTR-DOC is an accessible substrate for microbial respiration. If combined with optical analyses, PTR-MS would enrich our understanding of DOM dynamics by giving detailed molecular metrics (chemodiversity and oxidation state) alongside the LMW/HMW, autochthonous/allochthonous, and humic/nonhumic data provided by fluorescence and absorbance. The fact that the method is quantitative also potentially paves the way to understanding what portions of DOM are responsible for fluorescence properties. Additionally, as PTR-DOC increases proportionally with a decrease in DOC, it could be that PTR-MS would be a particularly useful tool in understanding marine and coastal DOM.

\section{ASSOCIATED CONTENT}

\section{Supporting Information}

The Supporting Information is available free of charge on the ACS Publications website at DOI: 10.1021/acs.estlett.8b00529.

Location map of sampling sites, depths and areas of sampled lakes, several additional figures displaying PTRMS data, two tables of statistical results, and detailed information concerning methods (PDF)

\section{AUTHOR INFORMATION}

\section{Corresponding Author}

*E-mail: michael.peacock@slu.se.

ORCID $\odot$

Mike Peacock: 0000-0002-3086-2854

\section{Notes}

The authors declare no competing financial interest.

The full PTR-MS data are available at Figshare: https:// figshare.com/s/53ab73e8f7f7a5084ee9. 


\section{ACKNOWLEDGMENTS}

D.M. acknowledges the support of The Netherlands Earth System Science Centre (NESSC) research network. The authors thank Susan Peacock who took part in the sampling campaign. At SLU, the authors thank Stephan Köhler and Claudia Cascone for providing use of the TOC analyzer and assistance with analysis. The authors thank Filip Moldan at the IVL Swedish Environmental Research Institute for logistical support and Daniel Mayor at the UK National Oceanography Centre for the loan of the PreSens system. The authors thank three anonymous reviewers who all provided useful comments and insights that significantly improved the manuscript. Finally, the authors acknowledge Chris Evans of $\mathrm{CEH}$ who instigated the sampling program.

\section{REFERENCES}

(1) Cole, J. J.; Prairie, Y. T.; Caraco, N. F.; McDowell, W. H.; Tranvik, L. J.; Striegl, R. G.; Duarte, C. M.; Kortelainen, P.; Downing, J. A.; Middelburg, J. J.; Melack, J. Plumbing the global carbon cycle: integrating inland waters into the terrestrial carbon budget. Ecosystems 2007, 10, 172-185.

(2) Moran, M. A.; Zepp, R. G. Role of photoreactions in the formation of biologically labile compounds from dissolved organic matter. Limnol. Oceanogr. 1997, 42, 1307-1316.

(3) Kellerman, A. M.; Kothawala, D. N.; Dittmar, T.; Tranvik, L. J. Persistence of dissolved organic matter in lakes related to its molecular characteristics. Nat. Geosci. 2015, 8, 454-457.

(4) Sobek, S.; Tranvik, L. J.; Prairie, Y. T.; Kortelainen, P.; Cole, J. J. Patterns and regulation of dissolved organic carbon: an analysis of 7,500 widely distributed lakes. Limnol. Oceanogr. 2007, 52, 12081219.

(5) Kothawala, D. N.; Stedmon, C. A.; Müller, R. A.; Weyhenmeyer, G. A.; Köhler, S. J.; Tranvik, L. J. Controls of dissolved organic matter quality: evidence from a large-scale boreal lake survey. Glob. Change Biol. 2014, 20, 1101-1114.

(6) Evans, C. D.; Futter, M. N.; Moldan, F.; Valinia, S.; Frogbrook, Z.; Kothawala, D. N. Variability in organic carbon reactivity across lake residence time and trophic gradients. Nat. Geosci. 2017, 10, 832835.

(7) Erlandsson, M.; Futter, M. N.; Kothawala, D. N.; Köhler, S. J. Variability in spectral absorbance metrics across boreal lake waters. J. Environ. Monit. 2012, 14, 2643-2652.

(8) Weishaar, J. L.; Aiken, G. R.; Bergamaschi, B. A.; Fram, M. S.; Fujii, R.; Mopper, K. Evaluation of specific ultraviolet absorbance as an indicator of the chemical composition and reactivity of dissolved organic carbon. Environ. Sci. Technol. 2003, 37, 4702-4708.

(9) Wilson, H. F.; Xenopoulos, M. A. Effects of agricultural land use on the composition of fluvial dissolved organic matter. Nat. Geosci. 2009, 2, 37-41.

(10) Frazier, S. W.; Nowack, K. O.; Goins, K. M.; Cannon, F. S.; Kaplan, L. A.; Hatcher, P. G. Characterization of organic matter from natural waters using tetramethylammonium hydroxide thermochemolysis GC-MS. J. Anal. Appl. Pyrolysis 2003, 70, 99-128.

(11) Kellerman, A. M.; Dittmar, T.; Kothawala, D. N.; Tranvik, L. J Chemodiversity of dissolved organic matter in lakes driven by climate and hydrology. Nat. Commun. 2014, 5, 3804.

(12) Mostovaya, A.; Hawkes, J. A.; Koehler, B.; Dittmar, T.; Tranvik, L. J. Emergence of the reactivity continuum of organic matter from kinetics of a multitude of individual molecular constituents. Environ. Sci. Technol. 2017, 51, 11571-11579.

(13) Hawkes, J. A.; Dittmar, T.; Patriarca, C.; Tranvik, L.; Bergquist, $\mathrm{J}$. Evaluation of the Orbitrap mass spectrometer for the molecular fingerprinting analysis of natural dissolved organic matter. Anal. Chem. 2016, 88, 7698-7704.

(14) Materić, D.; Peacock, M.; Kent, M.; Cook, S.; Gauci, V.; Röckmann, T.; Holzinger, R. Characterisation of the semi-volatile component of dissolved organic matter by thermal desorption - proton transfer reaction - mass spectrometry. Sci. Rep. 2017, 7, 15936.

(15) Hansel, A.; Jordan, A.; Holzinger, R.; Prazeller, P.; Vogel, W.; Lindinger, W. Proton transfer reaction mass spectrometry: on-line trace gas analysis at the $\mathrm{ppb}$ level. Int. J. Mass Spectrom. Ion Processes 1995, 149-150, 609-619.

(16) Holzinger, R.; Williams, J.; Herrmann, F.; Lelieveld, J.; Donahue, N. M.; Röckmann, T. Aerosol analysis using a ThermalDesorption Proton-Transfer-Reaction Mass Spectrometer (TD-PTRMS): a new approach to study processing of organic aerosols. Atmos. Chem. Phys. 2010, 10, 2257-2267.

(17) Materić, D.; Bruhn, D.; Turner, C.; Morgan, G.; Mason, N.; Gauci, V. Methods in plant foliar volatile organic compounds research. Appl. Plant Sci. 2015, 3, 1500044.

(18) Olsson, B.; Hallbäcken, L.; Johansson, S.; Melkerud, P.-A.; Nilsson, S. I.; Nilsson, T. The Lake Gårdsjön area - physiological and biological features. Ecol. Bull. 1985, 37, 10-28.

(19) Warkentin, M.; Freese, H. M.; Karsten, U.; Schumann, R. New and fast method to quantify respiration rates of bacterial and plankton communities in freshwater ecosystems by using optical oxygen sensor spots. Appl. Environ. Microbiol. 2007, 73, 6722-6729.

(20) McKnight, D. M.; Boyer, E. W.; Westerhoff, P. K.; Doran, P. T.; Kulbe, T.; Andersen, D. T. Spectrofluorometric characterization of dissolved organic matter for indication of precursor organic material and aromaticity. Limnol. Oceanogr. 2001, 46, 38-48.

(21) Ohno, T. Fluorescence inner-filtering correction for determining the humification index of dissolved organic matter. Environ. Sci. Technol. 2002, 36, 742-746.

(22) Fellman, J. B.; Hood, E.; Spencer, R. G. M. Fluorescence spectroscopy opens new windows into dissolved organic matter dynamics in freshwater ecosystems: A review. Limnol. Oceanogr. 2010, $55,2452-2462$.

(23) Holzinger, R. PTRwid: a new widget tool for processing PTRTOF-MS data. Atmos. Meas. Tech. 2015, 8, 3903-3922.

(24) Strohalm, M.; Kavan, D.; Novák, P.; Volný, M.; Havlícek, V. mMass 3: a cross-platform software environment for precise analysis of mass spectrometric data. Anal. Chem. 2010, 82, 4648-4651.

(25) Stubbins, A.; Lapierre, J.-F.; Berggren, M.; Prairie, Y. T.; Dittmar, T.; del Giorgio, P. A. What's in an EEM? Molecular signatures associated with dissolved organic fluorescence in boreal Canada. Environ. Sci. Technol. 2014, 48, 10598-10606.

(26) Shannon, C. E. A mathematical theory of communication. Bell Syst. Tech. J. 1948, 27, 379-423.

(27) Martínez-Pérez, A. M.; Nieto-Cid, M.; Osterholz, H.; Catalá, T. S.; Reche, I.; Dittmar, T.; Álvarez-Salgado, X. A. Linking optical and molecular signatures of dissolved organic matter in the Mediterranean Sea. Sci. Rep. 2017, 7, 3436.

(28) Persson, G.; Broberg, O. Nutrient concentrations in the acidified Lake Gårdsjön: the role of transport and retention of phosphorus, nitrogen and DOC in watershed and lake. Ecol. Bull. 1985, 37, 158-175.

(29) Hutchins, R. H. S.; Aukes, P.; Schiff, S. L.; Dittmar, T.; Prairie, Y. T.; del Giorgio, P. A. The optical, chemical, and molecular dissolved organic matter succession along a boreal soil-stream-river continuum. J. Geophys. Res.: Biogeosci. 2017, 122, 2892-2908.

(30) Mopper, K.; Kieber, D. J.; Stubbins, A. Marine photochemistry of organic matter: Processes and impacts. In Biogeochemistry of marine dissolved organic matter, 2nd ed.; Hansell, D. A., Carlson, C. A., Eds.; Academic Press: London, 2015; pp 389-450.

(31) Berggren, M.; Klaus, M.; Selvam, B. P.; Ström, L.; Laudon, H.; Jansson, M.; Karlsson, J. Quality transformation of dissolved organic carbon during water transit through lakes: contrasting controls by photochemical and biological processes. Biogeosciences 2018, 15, 457470.

(32) Chen, H.; Stubbins, A.; Perdue, E. M.; Green, N. W.; Helms, J. R.; Mopper, K.; Hatcher, P. G. Ultrahigh resolution mass spectrometric differentiation of dissolved organic matter isolated by coupled reverse osmosis-electrodialysis from various major oceanic water masses. Mar. Chem. 2014, 164, 48-59. 
(33) Marchand, D.; Prairie, Y. T.; Del Giorgio, P. A. Linking forest fires to lake metabolism and carbon dioxide emissions in the boreal region of Northern Québec. Glob. Change Biol. 2009, 15, 2861-2873.

(34) Medina-Sánchez, J. M.; Herrera, G.; Durán, C.; Villar-Argaiz, M.; Carrillo, P. Optode use to evaluate microbial planktonic respiration in oligotrophic ecosystems as an indicator of environmental stress. Aquat. Sci. 2017, 79, 529-541.

(35) Berggren, M.; Laudon, H.; Haei, M.; Ström, L.; Jansson, M. Efficient aquatic bacterial metabolism of dissolved low-molecularweight compounds from terrestrial sources. ISME J. 2010, 4, 408416.

(36) Tranvik, L. J. Bacterioplankton growth on fractions of dissolved organic carbon of different molecular weights from humic and clear waters. Appl. Environ. Microbiol. 1990, 56, 1672-1677.

(37) Mostovaya, A.; Hawkes, J. A.; Dittmar, T.; Tranvik, L. J. Molecular determinants of dissolved organic matter reactivity in lake water. Front. Earth Sci. 2017, 5, 106.

(38) Wagner, S.; Jaffé, R.; Cawley, K.; Dittmar, T.; Stubbins, A. Associations between the molecular and optical properties of dissolved organic matter in the Florida Everglades, a model coastal wetland system. Front. Chem. 2015, 3, 66. 